\title{
12 IDE NYATA AGAR BERHASIL MEMIMPIN SEKOLAH
}

\section{Indah Zakiyatul Mazidah}

Universitas Nahdlatul Ulama Sidoarjo

\section{LATAR BELAKANG}

Membangun hubungan adalah fondasi manajemen sekolah dan pendidikan bagi seorang kepala sekolah dan atau wirausahawan pendidikan. Saat siswa sekolah menengah menjalin hubungan dengan Anda, mereka akan menjadi sekutu terbesar Anda. Di sisi lain, jika mereka merasa Anda tidak adil atau tidak mau mendengarkan, tidak ada teknik manajemen yang akan menyelamatkan Anda. Ketika Anda mengembangkan rencana manajemen kelas Anda, pilih dan pilih ide-ide yang selaras dengan kepribadian dan gaya pengajaran Anda. Beri diri Anda waktu untuk bereksperimen dan mencerminkan mengetahui apa yang berhasil untuk satu kelompok, mungkin tidak bekerja dengan yang lain. Untungnya ada cara para pelaku kepala sekolah dan wirausahawan 
pendidikan memanfaatkan waktu mereka sebaikbaiknya. Berikut adalah beberapa tips dari arsip manajemen pendidikan bagi Kepala Sekolah dan wirausahawan pendidikan yang dapat membantu Anda memimpin dan mengelola sekolah Anda lebih efisien dan efektif.

\section{BERGABUNGLAH DENGAN MAESTRO}

Sama seperti jaringan, kadang-kadang Anda perlu berinvestasi secara finansial dalam pengembangan Anda sendiri. Kami melakukan ini melalui pendidikan berkelanjutan dan sekarang sudah biasa melakukan ini dengan dalang. Dengan bertemu secara teratur dengan para pemimpin yang setara, individu dapat mempercepat pengembangan kepemimpinan mereka dan menghancurkan tujuan pribadi dan profesional mereka (Bauer, 2019).

\section{MINDSET WIRAUSAHA}

Amanah, toleransi, bekerja sama, bertanggungjawab adalah prinsip wirausaha pendidikan (Nahdiyah, Amrina, Purnomo, \& Rosyidah, 2017). Edupreneur atau educational entrepreneur berasal dari dua kata yaitu education bermakna pendidikan dan entrepreneur bermakna pengusaha atau 
wirausahawan. Ada juga yang menyamakan istilah edupreneur dengan istilah teacherpreneur (Purnomo, 2017). Menjaga hubungan baik dengan wali siswa melalui melaksanakan janji dan pelayanan yang baik adalah bagian dari promosi wirausaha (Asitah, Usmawati, Rosyidah, \& Purnomo, 2017).

\section{BERDAYAKAN SISWA ANDA}

Guru merupakan seorang pendidik dan pengajar sekaligus sebagai pembentuk kepribadian siswa yang unggul, berwawasan dan baik (Maula et al., 2018). untuk membuat perubahan dalam suara, pilihan, kontribusi, kepemimpinan, tata kelola dan kemitraan internasional mereka. Dukung guru Anda untuk memandu pemberdayaan (Driscoll, 2018).

\section{PERGI KE KONFERENSI}

Tips kelola sekolah adalah senantiasa belajar dan bekerja keras. Bersabarlah dengan masalah, sesungguhnya didalam kesulitan ada kemudahan (Sholichah, Istiqomah, Rosyidah, \& Purnomo, 2017). Perjalanan. Belajar Jaringan Ini membuat seorang pemimpin lebih baik (Bauer, 2019). 


\section{MENANGANI MASALAH SEJAK AWAL}

Siswa perlu memahami apa yang diketahui dan apa yang diminta untuk memiliki kemampuan menjawab (Suci et al., 2018). Dianjurkan untuk menangani masalah sebelum menjadi terlalu besar untuk ditangani. Anda dapat mengatasi setiap masalah kecil yang terjadi di kelas. Kesalahan kecil dalam masalah disiplin bisa menjadi mimpi buruk di masa depan (Edsys, 2016).

\section{KASIH SANG KHOLIK}

Kisah pendidikan antara guru dan murid itu seperti aliran listrik dengan lampu. Bagaimana lampu itu bisa menyala kalau aliran listriknya juga mati ?. Bagaimana murid itu bisa berprestasi sedangkan guru sendiri tidak pernah berprestasi dan mendoakan (Fidiana, Istiana, Rosyidah, \& Purnomo, 2017). Setiap manusia hamba Tuhan yang memiliki ilmu selayaknya harus mengamalkan ilmu tersebut (Asitah et al., 2017). Pendidikan adalah kunci untuk membuka pintu emas kesuksesan. Wirausaha pendidikan dengan motivasi bisnis dengan Allah Ta'ala sebagai bentuk kenyamanan untuk ibadah. Tips mengelola institusi pendidikan adalah niat mendidik dan berjuang karena Allah ta'ala. Niscaya rintangan sebesar apapun akan terasa 
ringan dihadapan kita. Melihat anak mengenal Allah Ta'ala dan sukses akhlak dan pengetahuannya merupakan kebahagiaan pendidik (Yuniarti, Kautsari, Sholichah, Purnomo, \& Rosyidah, 2017). Prinsip pendidikan adalah sosial. Sebagai seorang guru, kita harus memiliki kepedulian sosial (Asitah et al., 2017). Guru harus bisa membangun generasi muda untuk masa depan. Hiduplah untuk mengamalkan ilmu (Sholichah et al., 2017).

\section{KARAKTER}

Pemimpin sekolah dan wirausaha pendidikan seharusnya senantiasa menikmati proses karena tidak ada hal yang besar yang tidak dilakukan dari hal yang kecil. Semua butuh proses, karena kesuksesan tidak datang secara langsung tanpa berproses (Maula, Mufidah, Rosyidah, \& Purnomo, 2017). Memahami bahwa sekolah membangun karakter. Seorang pemimpin yang efektif memiliki kekuatan untuk membantu siswa dan guru tumbuh dan belajar dengan cara yang mendalam (Drewitt, 2017). 


\section{JANGAN ABAIKAN BARANG KECIL}

Manajemen sekolah dilakukan dengan menerapkan standar kualitas dalam rekrutmen pengajar yaitu kedekatannya dengan amaliyah (Munjidah, Zannah, Purnomo, \& Rosyidah, 2017).

Suatu hari, siswa mulai menggambarkan berbagai celana yang saya kenakan untuk bekerja. Mereka secara akurat menceritakan setiap pasangan yang saya miliki. Dalam contoh lain, siswa mulai membaca pengumuman pertunangan saya (mereka mencari Google). Siswa memperhatikan saat mereka mencari untuk membuat koneksi. Ini bisa berupa sesuatu yang sederhana seperti ulang tahun bersama, menyukai musik yang sama, atau memiliki selera yang sama pada sepatu. Ini berarti Anda perlu memberikan informasi dan menciptakan peluang bagi siswa Anda untuk melihat diri mereka sendiri dalam diri Anda (Kane, 2018).

\section{MEMAHAMI KEHADIRAN}

Kesabaran dan komunikasi yang baik dengan masyarakat sekitar adalah kunci untuk dapat mengatasi masalah dan bisa bangkit dari keterpurukan manajemen pendidikan. Prinsip utama dan kepemimpinan wirausaha pendidikan 
adalah disiplin, kreatif, cerdas dan ulet (Qori' ah, Sholichah, Purnomo, \& Rosyidah, 2017). Panduan ini berfokus pada administrasi kehadiran, tingkat kehadiran di sekolah Anda, dan melampaui pengumpulan data (Educational Leaders, 2019).

\section{KAJIAN PENDIDIKAN}

Pendidikan Indonesia membutuhkan peningkatan akses, mutu dan relevansi pendidikan untuk memberi manfaat membangun bagi pendidikan dan rakyat Indonesia (Irawan et al., 2018). Guru merupakan seorang yag memilki tugas mulia sebagai pendidik dan pengajar sekaligus sebagai pembentuk kepribadian siswa (Maula et al., 2018). Bijaksana dan pantang menyerah dalam belajar adalah kunci kesuksesan. Pendidikan adalah pelajaran yang harus kita pelajari setiap hari baik dari buku, lingkungan, teman, maupun keluarga agar kita tidak tertinggal (Qori'ah et al., 2017). Hasil penelitian menunjukkan bahwa penerapan pembelajaran dapat meningkatkan prestasi siswa; dan tes menunjukkan bahwa prestasi belajar siswa kelas belajar lebih baik daripada siswa kelas konvensional (Iskandar, Rizal, Kurniasih, Sutiksno, \& Purnomo, 2018). Pendidikan itu sebuah perhiasan dalam 
kemakmuran dan tempat bernaung dalam kesengsaraan (Maula et al., 2017).

\section{JANGAN BERHARAP UNTUK MEMENANGKAN KONTES POPULARITAS}

Cara memimpin sekolah adalah senantiasa musyawarah serta sharing bersama para guru atau dengan siapapun dan tetap mendekat pada Allah SWT (Yuniarti et al., 2017). Keputusan yang harus Anda buat tidak akan menyenangkan semua orang. Lakukan apa yang benar, bukan apa yang akan membantu orang lain menyukai Anda (Drewitt, 2017).

\section{LATIH PEMIMPIN MASA DEPAN}

Pemimpin sekolah sebisanya tegas, toleran terhadap bawahannya dan mengayomi. Pendidikan adalah menyampaikan ilmu dan mentransformasi orang lain menjadi lebih baik (Fidiana et al., 2017). Para pemimpin hebat akan menginspirasi orang-orang yang bekerja di bawah mereka jika mereka memberi mereka yang telah tumbuh secara profesional lebih banyak tanggung jawab dan peran kepemimpinan. Sekolah lebih baik jika memiliki dua pemimpin hebat, bukan satu, 10 bukan lima. Para pemimpin 
hebat juga mencari orang-orang yang dapat mengisi posisi kepemimpinan di masa depan. Kepala sekolah yang hebat, misalnya, mencari staf pengajar yang berbakat yang memiliki kemampuan untuk memimpin departemen tempat mereka berada. Tentu saja, para pemimpin perlu mengkomunikasikan apa yang mereka lakukan, misalnya, seorang kepala departemen yang lebih tua akan membeli pelatihan kepala departemen masa depan yang lebih muda (Watanabe-Crockett, 2018). 


\section{REFERENCES}

Asitah, N., Usmawati, D. Z., Rosyidah, E., \& Purnomo, A. (2017). MI Hasyim Asy' ari Ilmu Harus Terus Mengarus. In Wirausaha Pendidikan Indonesia (Jilid 2). Sidoarjo: UNUSIDA Press.

Bauer, D. (2019). 200 Tips for Effective School

Leaders. Retrieved June 15, 2019, from https://www.betterleadersbetterschools.com/20 0-tips-effective-school-leaders/

Drewitt, P. (2017). 25 tips for School Principals.

Retrieved June 14, 2019, from

https://www.linkedin.com/pulse/25-tips-schoolprincipals-paul-drewitt

Driscoll, M. (2018). 16 Success Tips for New 21st

Century Principals. Retrieved June 27, 2019, from https://thinkstrategicforschools.com/16-successtips-new-21st-century-principals/

Edsys. (2016). 10 Awesome Tips to Manage School Discipline Issues. Retrieved June 25, 2019, from https://www.edsys.in/10-awesome-tips-tomanage-school-discipline-issues/

Educational Leaders. (2019). Guides for managing your school. Retrieved June 25, 2019, from http://www.educationalleaders.govt.nz/Managin g-your-school/Guides-for-managing-yourschool

Fidiana, W., Istiana, Z., Rosyidah, E., \& Purnomo, A. (2017). MINU Waru 2 Insan Berkilau Cahaya Manfaat. In Wirausaha Pendidikan Indonesia (Jilid 4). Sidoarjo: UNUSIDA Press. 
Irawan, D. E., Purnomo, A., Sutiksno, D. U., Abraham, J., Alamsyah, A., Saputra, D. H., $\cdots$ Rosyidah, E. (2018). Kajian Pendidikan Tinggi IDRI untuk DPR RI dan Ristek Dikti 2018. Bandung: ITB Press.

Iskandar, A., Rizal, M., Kurniasih, N., Sutiksno, D. U., \& Purnomo, A. (2018). The Effects of Multimedia Learning on Students Achievement in Terms of Cognitive Test Results. Journal of Physics:

Conference Series, 1114(1), 012019.

https://doi.org/10.1088/17426596/1114/1/012019

Kane, A. (2018). 5 Essential Tips for Managing High School Students. Retrieved June 28, 2019, from https://theartofeducation.edu/2018/07/02/5essential-tips-for-managing-high-schoolstudents/

Maula, I., Asitah, N., Munjidah, A., Nahdiyah, K., Yuniarti, D., Sholichah, S. A., ... Qori' ah, S. (2018). Kontribusi Kreativitas Guru SD dalam Induksi Pembelajaran.

https://doi.org/http://doi.org/10.17605/OSF.IO/B S795

Maula, I., Mufidah, F. I., Rosyidah, E., \& Purnomo, A. (2017). SD Antawirya Islamic Javanese School Mother is Culture. In Wirausaha Pendidikan Indonesia (Jilid 1). Sidoarjo: UNUSIDA Press.

Munjidah, A., Zannah, I. P. N., Purnomo, A., \& Rosyidah, E. (2017). MI Thoriqussalam Berpegang Kepada Rosul. In Wirausaha Pendidikan Indonesia (Jilid 4). Sidoarjo: UNUSIDA Press. 
Nahdiyah, K., Amrina, S., Purnomo, A., \& Rosyidah, E. (2017). SD Taman Pendidikan Islam Porong Iman Kuat Bekal di Akhirat. In Wirausaha Pendidikan Indonesia (Jilid 2). Sidoarjo: UNUSIDA Press. Purnomo, A. (2017). Pengertian Edupreneur.

https://doi.org/10.31227/osf.io/8fnu6 Qori' ah, S., Sholichah, S. A., Purnomo, A., \& Rosyidah, E. (2017). Progresif Bumi Sholawat dengan Kebenaran Semua Pasti Ada Jalan. In Wirausaha Pendidikan Indonesia (Jilid 3).

Sidoarjo: UNUSIDA Press.

Sholichah, S. A., Istiqomah, A., Rosyidah, E., \& Purnomo, A. (2017). MI Darun Najah Berfikir Berkarya Berdzikir. In Wirausaha Pendidikan Indonesia (Jilid 3). Sidoarjo: UNUSIDA Press.

Suci, S. H. A., Rosyidah, E., Asitah, N., Aini, N., Murni, A. W., Anam, F., ‥ Kuraesin, A. D. (2018).

Learning from Picture and Picture Action Research: Enhancement of Counting Ability on Division of Numbers for Primary School Students. Journal of Physics: Conference Series, 1114(1), 012044. https://doi.org/10.1088/17426596/1114/1/012044

Watanabe-Crockett, L. (2018). The 10 School Leadership Best Practices That Make a Difference. Retrieved June 24, 2019, from https://www.wabisabilearning.com/blog/10school-leadership-best-practices 
Yuniarti, D., Kautsari, M. F., Sholichah, F., Purnomo, A., \& Rosyidah, E. (2017). SMP SMA Al-Amin Ponpes Bahrul Hidayah Serahkan pada Allah Ta' ala. In Wirausaha Pendidikan Indonesia (Jilid 1). Sidoarjo: UNUSIDA Press. 